\title{
Talking With My Depressed Patients
}

\section{Consumer Satisfaction with a Novel Forum for Consultant Education}

\author{
Walter Braude, Senior Registrar in Psychiatry, Prestwich Hospital, Manchester
}

Education for consultants may appear to some to be a paradox. Consultants are often expected to be providers of an endless fund of knowledge, expertise and skill. Their own needs have perhaps been subordinated as a consequence. Traditionally education for consultants has been provided by postgraduate conferences where the participants are invariably passive recipients of a series of lectures. For the participant, weighted down by the excellence of the gastronomic hospitality, these occasions may become a personal battle against creeping postprandial somnolence, and are only enlivened by the conviviality of social encounters and renewed aquaintances. Their educational value may be less profound.

The Department of Psychiatry at the University of Manchester, in association with the North West Division of the Royal College of Psychiatrists, mooted the idea of a different form of educational forum for consultants. Consultants in the North West were invited to attend a day conference entitled 'Talking With My Depressed Patients'. This was billed as having an 'unusual format in that instead of sitting in a lecture theatre and listening to set pieces, we will meet in small groups and discuss our actual work with patients.' Eight consultants expressed a willingness to participate in the conference. Prior to the conference, Mr O'Dowd, Technical Manager in the Department of Psychiatry, visited each prospective participant in his own department and made videotape recordings of each consultant interviewing a depressed patient, currently in treatment. In addition, Mr O'Dowd also recorded the four group leaders interviewing depressed patients, in a similar manner.

\section{Conference}

Seven consultants (all consultants in general adult psychiatry) attended the conference. They were divided into two groups. The four group leaders (all members of the University of Manchester, Department of Psychiatry) were divided into two groupings-Professor Goldberg and Dr Tantam; Dr Maguire and Dr Creed. The consultant groups attended each pair of group leaders successively in the morning and afternoon sessions. In the sessions videotapes of the participants and the group leaders taken previously in the treatment setting, were shown and aspects of the interview and treatment situation were discussed. Videotapes taken of all participants were discussed. The role of the group leaders was to facilitate discussion concerning aspects of the interview and treatment process, and not to provide categorical directives or didactic teaching as to the 'correct way' of proceeding.

I was involved in this 'pilot' project as an 'objective outsider' who would evaluate consumer satisfaction with the conference and thus provide a lead as to its future viability as an education forum.

\section{Pre-conference questionnaire}

Prior to the conference the participants and the group leaders completed a questionnaire which asked of them the frequency with which they used various treatment strategies for depressed out-patients, their satisfaction with their own performance and their desire for change in this regard, and their expectations of the conference.

Table I indicates the frequency with which these treatment strategies are utilized by the participants. It shows, with some exceptions, little difference between the group of course leaders and that of the participants with regard to clinical practice. It seems reasonable to assume that this reflects mainstream general psychiatric practice. The exceptions include the propensity of the participants to use hypnotics more frequently than the group leaders. In addition, the participants tend to use 'friendly unstructured conversation' more often and 'insight-orientated psychotherapy' less often than the group leaders. This latter difference may reflect a real difference

TABle I

Frequency of treatment strategies

\begin{tabular}{ccc}
\hline Group leaders & Participants \\
$(n=4)$ & $(n=7)$ \\
Mean $\pm 1 S D$ & Mean $\pm 1 S D$ \\
(per cent) & (per cent) \\
\hline
\end{tabular}

In what percentage of out-patients with a depressive illness do you use the following techniques?

1. Antidepressant drugs

2. Hypnotics

3. Major tranquillisers

4. Modification of interpersonal

$74 \pm 15 \quad 82 \pm 15$

$10 \pm 8 \quad 30 \pm 20$

relationships:

(a) by seeing patients individually

$8 \pm 8 \quad 11 \pm 5$

(b) use of joint marita/family therapy

5. Modification of patients' daily activities

$75 \pm 28 \quad 78 \pm 26$

$35 \pm 20 \quad 38 \pm 25$

$55 \pm 28 \quad 34 \pm 17$

6. Insight orientated psychotherapy:

(a) short term (6-8 sessions) $\quad 43 \pm 30 \quad 24 \pm 30$

(b) long term (at least 6 months) $\quad 16 \pm 11 \quad 5 \pm 6$

7. Modification of patients' depressive view of themselves and their future prospects

8. Friendly unstructured conversation

$66 \pm 20 \quad 61 \pm 34$

9. Refer to other disciplines (e.g. OT; Psychol; PSW)

(a) for exclusive management $\quad 11 \pm 17 \quad 6 \pm 6$

(b) as an adjunct to your management 
with regard to the utilization of such techniques. Alternatively, it could be argued that this does not reflect a variation in clinical practice. Academic consultants (group leaders) may be more prone to label, what non-academic consultants (participants) regard as a friendly chat, as a specific form of psychotherapy. Satisfaction ratings with regard to the participants' performance in utilizing these treatment modalities were in the middle range of an ordinal scale.

The participants mentioned many possible expectations for the conference: these included increasing self-awareness and improving communication skills, technical help with specific interviewing treatment techniques (e.g. cognitive therapy), learning from colleagues and gaining reassurance. Two participants expressed an 'open mind' as to what they hoped to gain from the conference while only one mentioned a specific clinical focus to his expectations of the conference-help in the management of personality disordered patients with mood disturbance.

\section{Post-conference questionnaire}

On completion of the day's course, the participants completed a further questionnaire which monitored their satisfaction with the course. They were asked to rate it in terms of 'usefulness', 'enjoyment' and 'stimulation' value on a six-point scale where one represented an extremely negative response and six represented an extremely positive response. Table II indicates the mean ratings for both the group leaders and the participant group. It shows that the participants responded most favourably to the course according to the specified parameters.

TABLE II

Satisfaction ratings

\begin{tabular}{lcc}
\hline & $\begin{array}{c}\text { Group leaders } \\
(n=4) \\
\text { Mean } \pm 1 S D\end{array}$ & $\begin{array}{c}\text { Participants } \\
(n=7) \\
\text { Mean } \pm 1 S D\end{array}$ \\
\hline Usefulness & $3.8 \pm 1.0$ & $5.0 \pm 0.5$ \\
Enjoyment & $4.3 \pm 0.6$ & $4.9 \pm 1.0$ \\
Stimulation & $4.5 \pm 0.4$ & $4.9 \pm 0.6$ \\
\hline
\end{tabular}

Mean satisfaction ratings for the course based on a scale from 1 to 6 , where 1 represents an extreme negative response and 6 an extreme positive response.

In addition, three of the participants considered that the course would, and the other four participants thought that it may, alter their interviewing techniques. However, none thought it would alter his management of depressed patients.

Six of the seven participants indicated that they would be keen to attend a conference in this identical form again.

\section{Follow-up interviews with participants}

Thus the response of the consultant participants to this course can be seen to be very positive. I interviewed these consultants again individually, two to three weeks after the conference. I was struck by the enthusiasm each participant still retained for the course, although their reasons for this differed. These included:

1. The specific value of the course in improving interviewing techniques and communication skills.

2. The unique forum that the course offered for consultants to get together, unfettered by their daily chores, to discuss facets of the management of difficult patients.

3. The opportunity the course provided for exposure to specific psychotherapeutic techniques: for example, one of the participants with special expertise in cognitive therapy demonstrated these techniques on his videotape recording; this enabled two of the participants to be introduced to this form of treatment.

4. The 'reassurance' derived from this experience that one's clinical practice 'was seen to be acceptable to one's peers'. As an example of this, one of the consultant participants commented that this was the first time in a decade of being a consultant that his clinical practice had been exposed to the scrutiny of colleagues and that, although this was initially 'anxiety provoking', it had ultimately proved to be 'very reassuring'.

5. The value of using similar videotape feedback techniques to teach junior medical staff interviewing and communications skills.

Common to all comments about the conference, was the notion that this conference was about 'me' as a practising psychiatrist in 'my' clinic and it was for this reason considered by the participants to be more pertinent to consultant clinical practice than didactic teaching.

\section{Conclusion}

In terms of consumer satisfaction this consultant conference was undoubtedly successful. The responses of the participants, moreover, indicate further possibilities, using similar techniques for future consultant educational meetings. These may, for example, include forums for the acquisition of specific psychotherapeutic techniques or regular meetings for consultants to discuss, via videotape feedback, the management of difficult patients.

Videotape feedback has already been shown to be a most useful facility in the teaching of interviewing and communication skills to medical students, ${ }^{1}$ trainee psychiatrists ${ }^{2}$ and family doctors. ${ }^{3}$ This meeting has provided another setting for its educational use.

\section{REFERENCES}

iMaguire, G. P., Roe, P., Goldberg, D. P., Jones, S., Hyde, C. \& O'Dowb, T. (1978) The value of feed-back in teaching interview skills to medical students. Psychological Medicine, 8, 695704.

2Goldberg, D. P., Hobson, R. F., Margison, F., Moss, S. \& O'Dowd, T. (1984) Evaluating the teaching of a method of psychotherapy. British Journal of Psychiatry, 144, 575-580.

3 Goldaenc, D. P., Stezle, J. J. \& SMrth, C. (1980) Teaching psychiatric interview techniques to family doctors. Acta Psychiatrica Scandinavica, Supplement 285, 62, 41-49. 